\title{
Morphological and Functional Alterations of the Ductus Arteriosus in a Chicken Model of Hypoxia-Induced Fetal Growth Retardation
}

\author{
SASKIA VAN DER STERREN, PIA ÅGREN, BEA ZOER, LILIAN KESSELS, CARLOS E. BLANCO, AND EDUARDO VILLAMOR \\ Department of Pediatrics, Maastricht University Medical Centre, GROW School for Oncology and Developmental Biology, 6202 AZ \\ Maastricht, The Netherlands
}

\begin{abstract}
The hypoxic conditions in which children with intrauterine growth retardation (IUGR) develop are hypothesized to alter the development of the ductus arteriosus (DA). We aimed to evaluate the effects of in ovo hypoxia on chicken DA morphometry and reactivity. Hypoxia $\left(15 \% \mathrm{O}_{2}\right.$ from day 6 to 19 of the 21-d incubation period) produced a reduction in the body mass of the 19-d fetuses and a shortening of right and left DAs. However, ductal lumen and media cross-sectional areas were not affected by hypoxia. The ductal contractions induced by oxygen, $\mathrm{KCl}, \mathrm{H}_{2} \mathrm{O}_{2}$, 4-aminopyridine, and endothelin-1 were similar in control and hypoxic fetuses. In contrast, the DAs from the hypoxic fetuses showed increased contractile responses to norepinephrine and phenylephrine and impaired relaxations to acetylcholine, sodium nitroprusside, and isoproterenol. The relaxations induced by 8-Br-cGMP, forskolin, Y-27632, and hydroxyfasudil were not altered by chronic hypoxia. In conclusion, chronic in ovo hypoxia-induced growth retardation in fetal chickens and altered the response of the DA to adrenergic agonists and to endothelium-dependent and -independent relaxing agents. Our observations support the concept that prolonged patency of the DA in infants with IUGR may be partially related with hypoxia-induced changes in local vascular mechanisms. (Pediatr Res 65: 279-284, 2009)
\end{abstract}

$\mathrm{I}^{\mathrm{n}}$ ntrauterine growth retardation (IUGR) is most frequently the consequence of placental insufficiency resulting in decreased availability of nutrients and oxygen (1). Although IUGR is considered as an important cause of pre- and postnatal morbidity, its impact on the several areas of morbidity associated with prematurity remains controversial. Reports vary from higher to similar rates of respiratory distress syndrome, chronic lung disease, necrotizing enterocolitis, retinopathy of prematurity, and patent ductus arteriosus (DA) in preterm infants with and without IUGR $(1,2)$.

The putative alterations produced by hypoxia and other prenatal insults in the normal development of DA are unclear. Histologic evidence of accelerated maturation of the DA was described in the autopsy of preterm infants exposed to chronic intrauterine stress, leading to the hypothesis that this may have resulted clinically in effective postnatal DA closure (3). In contrast, other authors have described in the DA of premature infants with IUGR, histologic changes, such as fragmentation, coagulation, necrosis of the internal elastic lamina, hemorrhage with

Received August 4, 2008; accepted September 25, 2008.

Correspondence: Eduardo Villamor, M.D., Ph.D., Department of Pediatrics, Maastricht University Medical Centre (MUMC+), P. Debyelaan 25, P.O. Box 5800, 6202 AZ Maastricht, The Netherlands; e-mail: E.Villamor@mumc.nl necrosis, and loosening of elastic fibers and muscles in the tunica media that may have produced subsequent patent DA (4).

The chicken fetus is an excellent model for the study of the cardiovascular consequences of prenatal growth retardation (5-7). Recently, we have studied the chicken DA reactivity and demonstrated that the effects of vasoactive mediators on its tone are developmentally regulated with loss of responsiveness to vasodilators and increase of responsiveness to vasoconstrictors with advancing age $(8-10)$.

Hypoxia has profound effects on endothelial and vascular smooth muscle cellular physiology affecting the transcriptionally regulated expression of vasoactive substances, the modulation of receptor populations, the density and activities of ion channels, and the signal transduction pathways involved in modulating vascular tone $(5-7,11-14)$. Postnatal constriction of the full-term DA produces hypoxia of the muscle media, and this stimulus appears as essential for the anatomic remodeling that prevents subsequent ductal reopening (15). In the present study, we hypothesize that prolonged hypoxic exposure alters the development of the DA contractile apparatus that is essential for rapid constriction after birth. Therefore, our aim was to evaluate the effects of in ovo hypoxia on the chicken DA reactivity and morphology.

\section{METHODS}

Incubation and hypoxia protocol. Experiments were performed in accordance with Dutch law for animal experimentation and were approved by the Ethical Committee of the University of Maastricht. Fertile Lohman-selected White Leghorn eggs were incubated at $37.8^{\circ} \mathrm{C}$ and $45 \%$ humidity (Incubator model 25HS, Masalles Comercial, Spain). Control embryos were incubated under normoxic conditions $\left(21 \% \mathrm{O}_{2}, 0.03 \% \mathrm{CO}_{2}\right)$. Experimental embryos were incubated under normoxic conditions until day 6 of incubation when eggs were transferred to a second incubator where hypoxia $(15.0 \pm 0.3 \%$ atmospheric $\mathrm{O}_{2}, 0.03 \% \mathrm{CO}_{2}$ ) was maintained by providing a constant flow of $\mathrm{N}_{2}$ and compressed air with a flow meter. The $\mathrm{O}_{2}$ and $\mathrm{CO}_{2}$ concentrations in the incubator were monitored with a DrDAQ $\mathrm{O}_{2}$ sensor (Pico Technology, United Kingdom) and an infrared $\mathrm{CO}_{2}$ analyzer (Beckman Instruments, Inc., Fullerton, CA).

Morphometric analysis of the DA. On day 19 of incubation, the embryos were taken out and immediately killed by decapitation. With the aid of a dissecting microscope (Mild M8; Leica, Cambridge, United Kingdom), the

\footnotetext{
Abbreviations: 4-AP, 4-aminopyridine; ACh, acetylcholine; cGMP, cyclic GMP; CSA, cross-sectional area; ET-1, endothelin-1; KRB, KrebsRinger bicarbonate; $\mathbf{K}_{\mathbf{V}}$, voltage-gated $\mathrm{K}^{+}$channels; NE, norepinephrine; $\mathbf{p D}_{\mathbf{2}},-\log \mathrm{EC}_{50} ;$ Phe, phenylephrine; sGC, soluble guanylate cyclase; SNP, sodium nitroprusside
} 

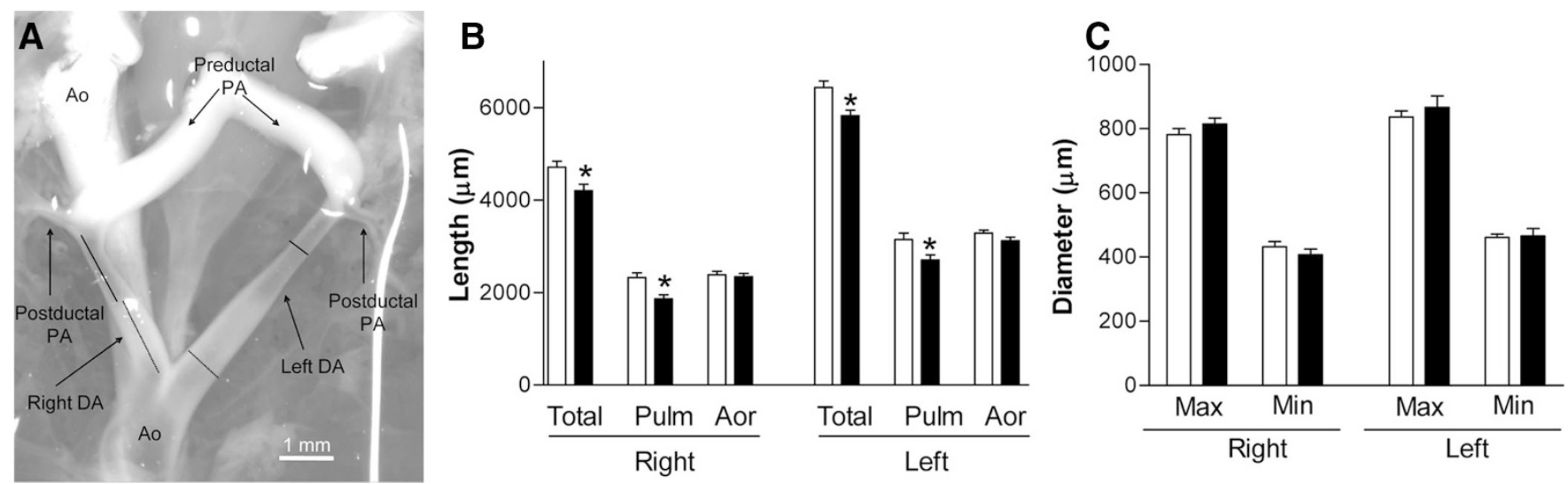

Figure 1. Anatomy of the chicken DA. The method used to determine the length and diameter of the pulmonary (solid line) and the aortic (dashed line) of the DAs is also depicted. Ao, aorta; PA, pulmonary artery. Lengths $(B)$ and diameters $(C)$ of the DAs of 19-d chicken fetuses exposed to hypoxia $(\square)$ or normoxia ( $\square$ ) during incubation. Pulm, pulmonary side; Aor, aortic side. Each bar represents the mean \pm SEM of eight animals. * $p<0.05$ for difference from normoxia.

heart, the esophagus and the crop were removed, the right and the left DA were exposed, and the preparation was photographed (Fig. 1) with a digital camera (Leica DFC 280). Pictures were subsequently analyzed with a computerized morphometric system (Quantimet 570C; Leica,). Analysis was performed by a single observer (P.A.), who was unaware of the experimental conditions. The total length of the DAs, the length of the aortic and the pulmonary segments, and the maximal and minimal diameters were determined. Each measurement was repeated three times and the mean value recorded.

Microscopic morphometric analysis was assessed in DAs fixed in situ with the whole-body freezing technique. Embryos were frozen in $1 \%$ carboxymethylcellulose in liquid nitrogen. Serial, transversal sections ( $8 \mu \mathrm{m}$ thick) through the whole length of the DAs, were obtained on a Leica freezing microtome (CM 3050S) and double staining was performed for elastin (Lawson solution; Klinipath, Duiven, The Netherlands) and a MAb against smooth muscle $\alpha$-actin (Dako, Carpinteria, CA). Microscopic images were analyzed with the Quantimet 570C to determine media layer cross-sectional area (CSA), media wall thickness, and intraluminal CSA. This analysis was only performed in the right DA because its orientation allowed the obtention of transversal sections of the vessel (Fig. 2). From each specimen, 3-5 sections with the morphology of the pulmonary side and 8-10 with the morphology of the aortic side of the DA were analyzed. Sections with a transitional morphology between the two parts were discarded for analysis. Analysis was performed by a single observer (L.K.), who was unaware of the experimental conditions.

\section{Recording of DA reactivity}

Reactivity was analyzed only in the proximal (pulmonary) side of the vessel. Rings from hypoxic and normoxic embryos were studied in parallel. The myograph organ bath was filled with Krebs-Ringer bicarbonate (KRB) buffer maintained at $39^{\circ} \mathrm{C}$ and continuously aerated with one of the following gas mixtures: $95 \% \mathrm{~N}_{2} / 5 \% \mathrm{CO}_{2}\left(\mathrm{Po}_{2}=2.6-3.3 \mathrm{kPa}\right), 5 \% \mathrm{O}_{2} / 90 \% \mathrm{~N}_{2} / 5 \% \mathrm{CO}_{2}$ $\left(\mathrm{Po}_{2}=6.8-7.2 \mathrm{kPa}\right)$, or $21 \% \mathrm{O}_{2} / 74 \% \mathrm{~N}_{2} / 5 \% \mathrm{CO}_{2}\left(\mathrm{Po}_{2}=16-20 \mathrm{kPa}\right)$. The final $\mathrm{pH}$ was $7.38-7.42$ and $\mathrm{PCO}_{2}$ was $4.6-5.6 \mathrm{kPa}$ in all solutions (8). Each DA ring was stretched to its individual optimal lumen diameter, i.e., the diameter at which it developed the strongest contractile response to $62.5 \mathrm{mM}$ $\mathrm{KCl}(8)$. During the first phase of stabilization and determination of optimal diameter, $\mathrm{KRB}$ buffer was aerated with $95 \% \mathrm{~N}_{2} / 5 \% \mathrm{CO}_{2}$. Afterward, and depending on the specific protocol, one of the above-described gas mixtures was used.

To assess the responsiveness of the DA to oxygen, vessels were incubated for 30 min with $95 \% \mathrm{~N}_{2} / 5 \% \mathrm{CO}_{2}$. Then the gas mixture was switched to $21 \%$ $\mathrm{O}_{2} / 74 \% \mathrm{~N}_{2} / 5 \% \mathrm{CO}_{2}$. This gas was maintained for $10 \mathrm{~min}$. In another set of experiments, the organ chamber was bubbled with 5\% $\mathrm{O}_{2} / 90 \% \mathrm{~N}_{2} / 5 \% \mathrm{CO}_{2}$ and concentration-response curves to $\mathrm{KCl}$, the inhibitor of voltage-gated $\left(\mathrm{K}_{\mathrm{V}}\right)$ $\mathrm{K}^{+}$channels 4-aminopyridine (4-AP), $\mathrm{H}_{2} \mathrm{O}_{2}$, endothelin-1 (ET-1), norepinephrine (NE), and phenylephrine (Phe) were constructed. Relaxing agonists were evaluated during contraction induced by $62.5 \mathrm{mM} \mathrm{K}^{+}$. Concentrationresponse curves for acetylcholine (ACh), the nitric oxide (NO) donor sodium nitroprusside (SNP), the cGMP (cGMP) analog 8-Br-cGMP, the $\beta$-adrenoceptor agonist isoproterenol, the adenylyl cyclase activator forskolin, and the Rho-kinase inhibitors Y-27632 and hydroxyfasudil were constructed.
Drugs and solutions. $\mathrm{KRB}$ contained (in $\mathrm{mmol} / \mathrm{L}$ ): $\mathrm{NaCl}, 118.5 ; \mathrm{KCl}$, 4.75; $\mathrm{MgSO}_{4} \cdot 7 \mathrm{H}_{2} \mathrm{O}, 1.2 ; \mathrm{KH}_{2} \mathrm{PO}_{4}, 1.2 ; \mathrm{NaHCO}_{3}, 25.0 ; \mathrm{CaCl}_{2}, 2.5$; glucose, 5.5. Solutions containing different concentrations of $\mathrm{K}^{+}$were prepared by replacing part of the $\mathrm{NaCl}$ by an equimolar amount of $\mathrm{KCl}$. All the drugs were obtained from Sigma Chemical Co (St. Louis, MO) and dissolved initially in distilled deionized water (except forskolin in ethanol).

Data analysis. Results are shown as mean (SD) of measurements in $n$ animals. For clarity, results in the figures are shown as mean \pm SEM. Contractions are expressed in Newton/meter and relaxations as percentage of reduction of the contraction induced by $\mathrm{K}^{+}$. Sensitivity (expressed as $\left.\mathrm{pD}_{2}=-\log \mathrm{EC}_{50}\right)$ and maximal contraction or relaxation $\left(E_{\max }\right)$ to agonists was determined by fitting individual concentration-response data to a nonlinear sigmoidal regression curve. Comparisons were made by an unpaired $t$ test. Differences were considered significant at a $p<0.05$.

\section{RESULTS}

Fetal growth and DA morphometry. Exposure of chicken fetuses to $15 \%$ instead of $21 \% \mathrm{O}_{2}$ from day 6 to day 19 of incubation induced growth retardation (body mass normoxic: $29.9 \mathrm{~g}$, SD 5.6, $n=34$; hypoxic: 25.3 , SD 5.5, $n=32, p<$ 0.01 versus normoxic).

Both the right and the left DAs were shorter in the hypoxic fetuses (Fig. 1B). When the lengths of pulmonary and the aortic sides of the DA were analyzed, it was observed that the ductal shortening induced by hypoxia was due to a shortening of the pulmonary segment (Fig. $1 B$ ). The external diameter of the DA was not significantly different between normoxic and hypoxic fetuses (Fig. 1C).

As shown in Fig. 2, the chicken DAs exhibited two distinct phenotypes along their lengths. The proximal (pulmonary) DA displayed the structure of a muscular artery with a dense $\alpha$-actin-positive media subjacent to the endothelium and few layers of elastic fibers around the muscular layer. The distal (aortic) DA contains many elastic fibers that fill the vascular wall arranged in concentric lamellae with $\alpha$-actin-positive smooth muscle cells embedded between the lamellae. The muscular phenotype was present in $49.4 \%$ (SD 8.7, $n=5$ ) of the length of the right DA from the normoxic animals and in $33.0 \%$ (SD 11.5, $n=5, p<0.05$ versus control) of the vessel length from the hypoxic group. The lumen CSA was significantly greater in the pulmonary than the aortic side of the DA and the media CSA was significantly greater in the aortic than 
A
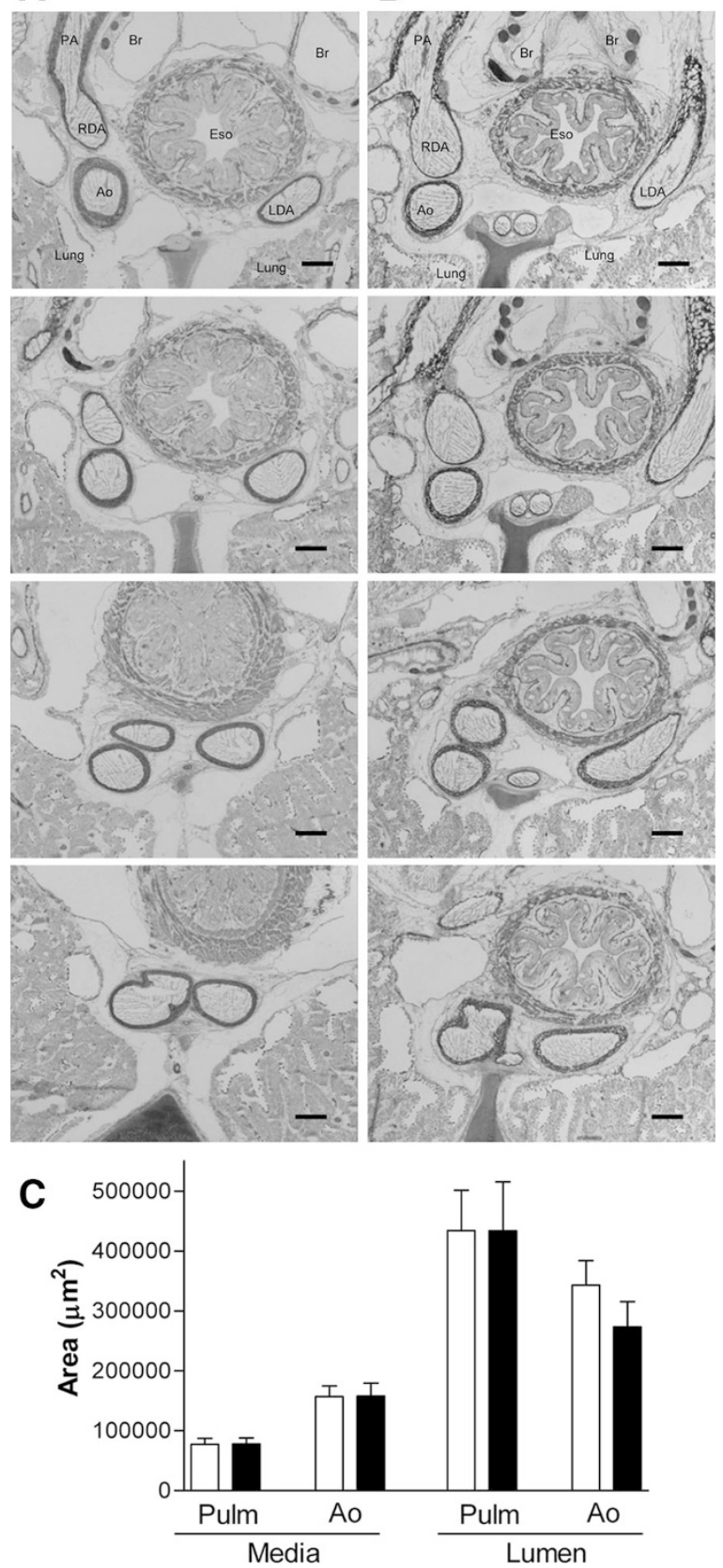

Figure 2. Histology of the chicken DA. Light micrographs showing double staining for elastin and $\alpha$-actin of cross-sections of snap-frozen 19-d chicken fetuses exposed to normoxia $(A)$ or hypoxia $(B)$ during incubation. Bars 200 $\mu \mathrm{M}$. Ao, aorta; PA, pulmonary artery; Eso, esophagus; $\mathrm{Br}$, bronchus; $\mathrm{R}$, right; $\mathrm{L}$, left. $(C)$ The media and lumen cross-sectional areas of the right DA were not significantly different between normoxic $(\square)$ and hypoxic ( $\square$ ) fetuses. Each bar represents the mean \pm SEM of five animals.

in the pulmonary side of the vessel. The media and lumen CSAs of the right DA were not significantly different between normoxic and hypoxic fetuses (Fig. 2C).

DA reactivity. Switching the $\mathrm{O}_{2}$ mixture from 0 to $21 \%$ (3 to $18 \mathrm{kPa}$ ) produced a progressive increase of the $\mathrm{O}_{2}$ concentration in the organ chamber that reached a steady state after $\sim 3$ min (8). This increase in $\mathrm{O}_{2}$ concentration resulted in a contractile response of the DA that was not significantly different between hypoxic and normoxic fetuses (Fig. 3A). In addition, the contractions induced by 4 -AP (Fig. $3 \mathrm{~A}$ ), $\mathrm{KCl}$ (Fig. $3 B ; \mathrm{pD}_{2}$ normoxic: $1.61, \mathrm{SD} 0.12$; hypoxic: $1.69, \mathrm{SD}$ $0.14 ; p>0.05$ ), $\mathrm{H}_{2} \mathrm{O}_{2}$ (Fig. 3C), and ET-1 (Fig. 3D) did not vary between the experimental groups. The diameter at which maximal responses to depolarizing high- $\mathrm{K}^{+}$solution were obtained was significantly higher in the DAs from the hypoxic fetuses $(843.1 \mu \mathrm{m}, \mathrm{SD} 92.31, n=32$ versus $775.8 \mu \mathrm{m}$, SD 92.3, $n=32 ; p<0.05)$, but the passive wall stretch induced by this optimal diameter was not significantly different (normoxia: $0.89 \mathrm{~N} / \mathrm{m}$, SD 0.19; hypoxia: $0.92 \mathrm{~N} / \mathrm{m}$, SD 0.24).

The adrenergic agonists NE (Fig. $3 E$ ) and Phe (Fig. $3 F$ ) induced significantly $(p<0.05)$ larger contractions in the DAs from the hypoxic (NE: $0.91 \mathrm{~N} / \mathrm{m}, \mathrm{SD} 0.22, n=11$; Phe:0.87 $\mathrm{N} / \mathrm{m}, \mathrm{SD} 0.20, n=11)$ than in those from the normoxic fetuses (NE: $0.72 \mathrm{~N} / \mathrm{m}$, SD 0.23, $n=11$; Phe:0.69 N/m, SD $0.18, n=11$ ). However, the sensitivity $\left(\mathrm{pD}_{2}\right)$ to $\mathrm{NE}$ (normoxic: 6.67, SD 0.22; hypoxic: 6.65, SD 0.23) and Phe (normoxic: 5.42, SD 0.15; hypoxic: 5.45, SD 0.17) did not vary between the experimental groups.

Acetylcholine (Fig. 4A), SNP (Fig. 4B), 8-Br-cGMP (Fig. $4 C$ ), isoproterenol (Fig. 5A), forskolin (Fig. 5B), Y-27632 (Fig. 5C), and hydroxyfasudil (Fig. 5D) relaxed DA rings (precontracted with $62.5 \mathrm{mM} \mathrm{KCl}$ ) in a concentrationdependent manner. The relaxations induced by ACh $\left(E_{\max }\right.$ normoxic: $39.49 \%, \mathrm{SD} 16.2, n=8 ; E_{\max }$ hypoxic: $15.02 \%$, SD 10.2, $n=8, p<0.05$ versus normoxic), $\operatorname{SNP}\left(E_{\max }\right.$ normoxic: $59.9 \%, \mathrm{SD} 27.7, n=8 ; E_{\max }$ hypoxic: $33.1 \%$, SD $16.4, n=8, p<0.05$ versus normoxic), and isoproterenol $\left(E_{\max }\right.$ normoxic: $168.1 \%, \mathrm{SD} 19.4, n=8 ; E_{\max }$ hypoxic: $112 \%$, SD $16.4, n=8, p<0.05$ versus normoxic) were significantly impaired in the DAs from the fetuses incubated under hypoxic conditions. The sensitivity to SNP was significantly greater in normoxic than in hypoxic fetuses $\mathrm{pD}_{2}$ normoxic: 5.84, $\mathrm{SD} 0.4 ; \mathrm{pD}_{2}$ hypoxic 4.95 , $\mathrm{SD} 0.41, p<0.01$ versus normoxic). The sensitivities to ACh and isoproteronol did not differ significantly between groups. The relaxations induced by 8 -Br-cGMP, forskolin, Y-27632, and hydroxyfasudil were not significantly different when normoxic and hypoxic DAs were compared.

\section{DISCUSSION}

We have characterized the morphologic and functional status of the DA in a chicken model of hypoxia-induced fetal growth retardation (5-7). We did not find significant evidences for an accelerated or delayed anatomical remodeling of the DA in the growth-retarded chicken fetuses. In contrast, the DA of the hypoxic fetuses showed an enhanced contractile response to $\alpha$-adrenergic agonists and an impaired relaxation to the $\beta$-adrenoceptor agonist isoproterenol, the endotheliumdependent vasodilator acetylcholine and the endotheliumindependent vasodilator SNP.

The DA belongs to a specialized system of $\mathrm{O}_{2}$-sensitive organs and tissues in the body that includes, among others, the pulmonary arteries, the carotid body, and the neuroepithelial body, which share striking similarities in the ways they respond to changes in $\mathrm{O}_{2}$ tension $(16,17)$. The mechanism proposed to explain $\mathrm{O}_{2}$-induced ductal contraction includes a 

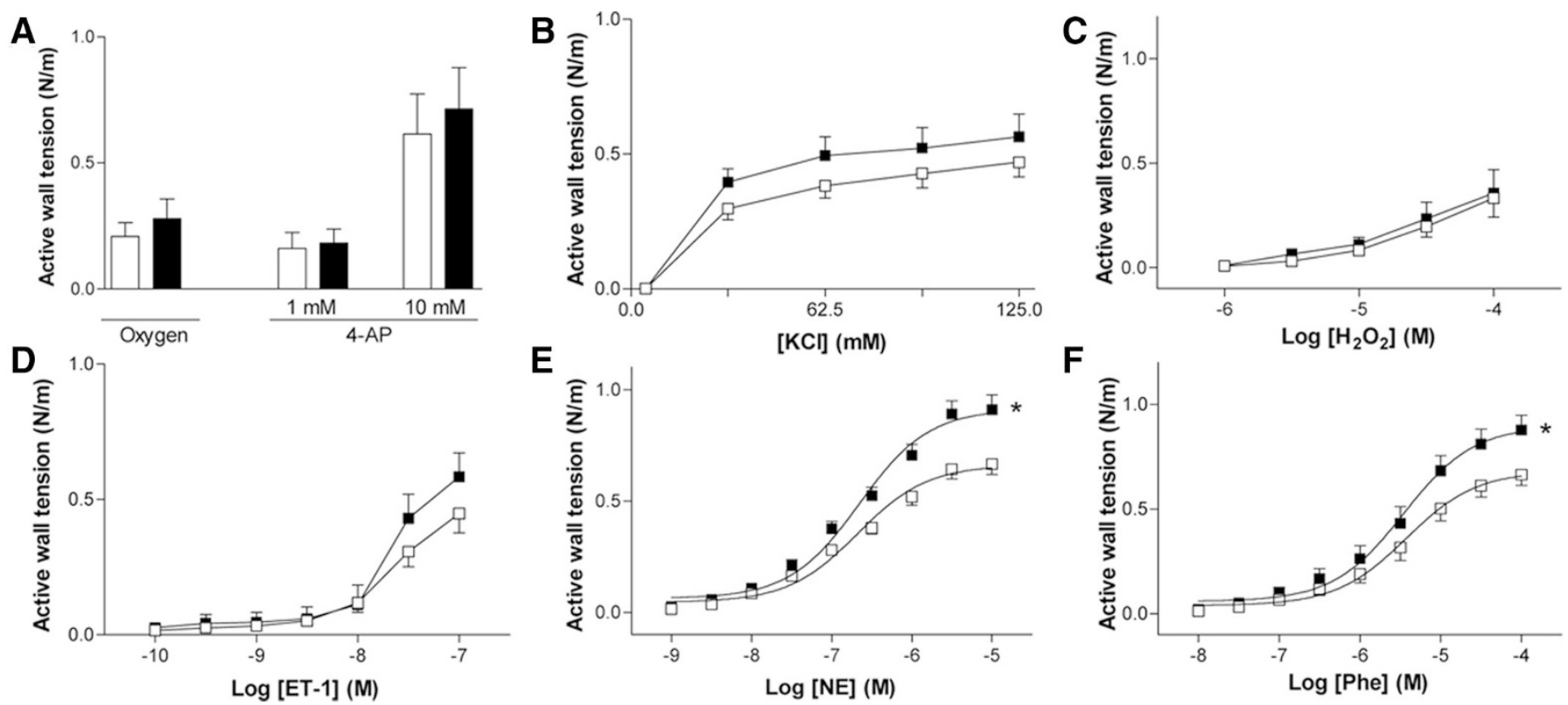

Figure 3. Contractile effects of oxygen, 4-AP, $\mathrm{KCl}, \mathrm{H}_{2} \mathrm{O}_{2}, \mathrm{ET}-1$, norepinephrine, and phenylephrine in DA rings of 19-d chicken fetuses exposed to hypoxia or normoxia ( $\square$ ) during incubation. Each point (or bar) represents the mean \pm SEM of $8-11$ animals. ${ }^{*} p<0.05$ for difference in $E_{\max }$ from normoxia.
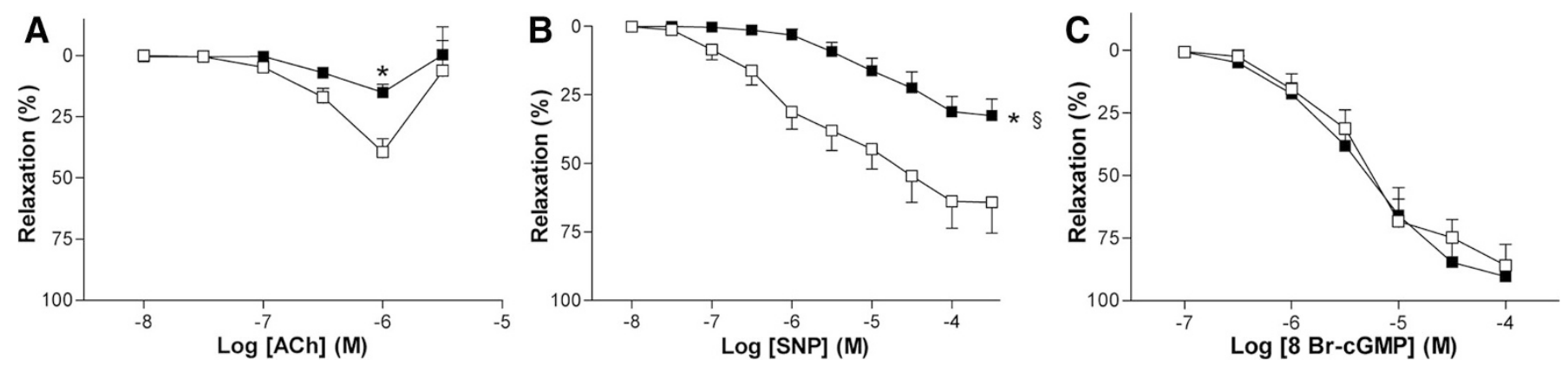

Figure 4. Concentration-dependent relaxant effects of acetylcholine, SNP, and 8-Br cGMP in DA rings of 19-d chicken fetuses incubated under hypoxia ( $\square$ ) or normoxia $(\square)$. Each point represents the mean \pm SEM of 6-11 animals. ${ }^{*} p<0.05$ for difference in $E_{\max }$ from normoxia. $\$ p<0.05$ for difference in $\mathrm{pD} \mathrm{D}_{2}$ from normoxia.

sensor: the electron transport chain of the mitochondria that increases production of reactive oxygen species, particularly $\mathrm{H}_{2} \mathrm{O}_{2}$, in response to changes in $\mathrm{O}_{2}$ levels. $\mathrm{H}_{2} \mathrm{O}_{2}$ can reach the cell membrane and decrease the opening of $\mathrm{K}_{\mathrm{V}}$ channels. This causes DA depolarization, opening of the voltage-gated $\mathrm{Ca}^{2+}$ channels, increase in intracellular $\mathrm{Ca}^{2+}$, and vasoconstriction $(16,17)$. Preliminary results of our laboratory indicate that this "mitochondria- $\mathrm{H}_{2} \mathrm{O}_{2}-\mathrm{K}_{\mathrm{V}}$ channels" axis is also involved in the response of chicken DA to $\mathrm{O}_{2}$ (8, and unpublished results). Although chronic hypoxia could putatively alter each component of the above axis (18), we have not observed any hypoxia-induced alteration of the chicken DA response to oxygen. Moreover, the contractions induced by high- $\mathrm{K}^{+}$depolarizing solution, the $\mathrm{K}_{\mathrm{V}}$ channel blocker 4-AP, and $\mathrm{H}_{2} \mathrm{O}_{2}$ were not significantly affected by chronic hypoxia.

Within the vasculature in general, chronic hypoxia produces a broad spectrum of structural and functional changes that are typically organ specific (18). As reported elsewhere, chronic moderate hypoxia in the chicken fetus led, in the femoral artery, to impairment of endothelium-dependent relaxation $(6,7)$ and increased periarterial sympathetic innervation (5), whereas in the pulmonary arteries led to an impairment of the responsiveness to several vasoconstrictors but did not affect endothelium-dependent or -independent relaxations (7). In the present work, we observed that chronic hypoxia impaired ACh- and SNP-mediated relaxations of the DA. Previously, we demonstrated that ACh induces endothelium-dependent relaxation of the chicken DA and that $\mathrm{NO}$ and endothelium derived hyperpolarizing factor are involved in this response (9). On the other hand, SNP evoked endothelium-independent relaxation of the chicken DA through the activation of soluble guanylate cyclase (sGC) (9). Therefore, the $\mathrm{NO} / \mathrm{sGC} / \mathrm{cGMP}$ axis is active in the chicken DA and our present results indicate that chronic hypoxia induced an impairment of this vasodilatory pathway. It should be noted that, in the present work, we studied the effects of relaxant agonists in DA rings contracted with high- $\mathrm{K}^{+}$depolarizing solution. Thus, the contribution of hyperpolarizing mechanisms to relaxation could not be analyzed in our experiments. In relation to the vascular effects of chronic hypoxia, numerous investigations have examined the involvement of the NO/sGC/cGMP axis in pulmonary and systemic vessels. The majority of these studies report hypoxiainduced endothelial impairment with normal response to $\mathrm{NO}$ donors $(19,20)$. However, other authors report alterations in both endothelium-dependent and -independent relaxation after expo- 

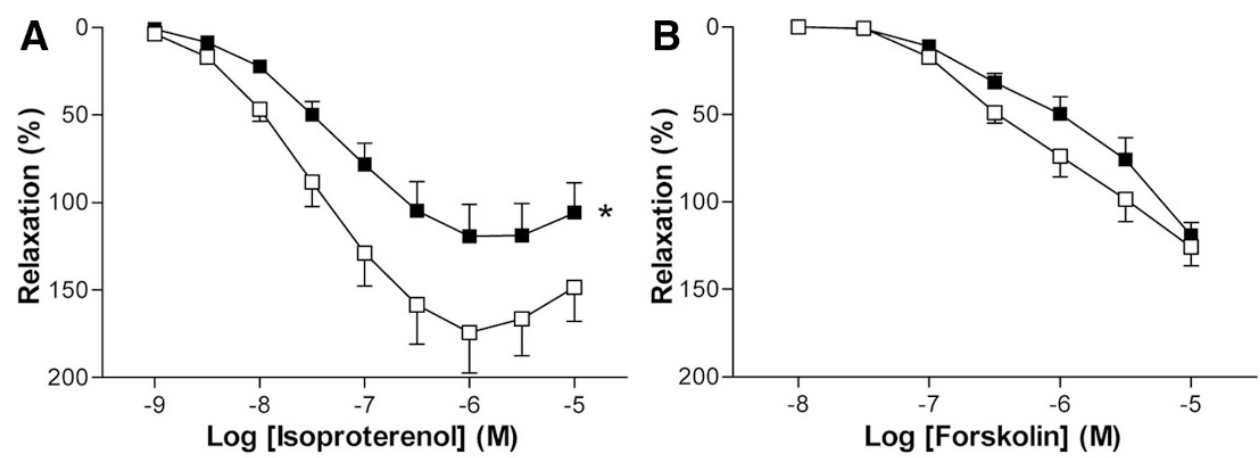

Figure 5. Concentration-dependent relaxant effects of isoproterenol, forskolin, Y-27632, and hydroxyfasudil in DA rings of 19-d chicken fetuses incubated under hypoxia ( $\square$ ) or normoxia $(\square)$. Each point represents the mean \pm SEM of 6-11 animals. $* p<0.05$ for difference in $E_{\max }$ from normoxia.
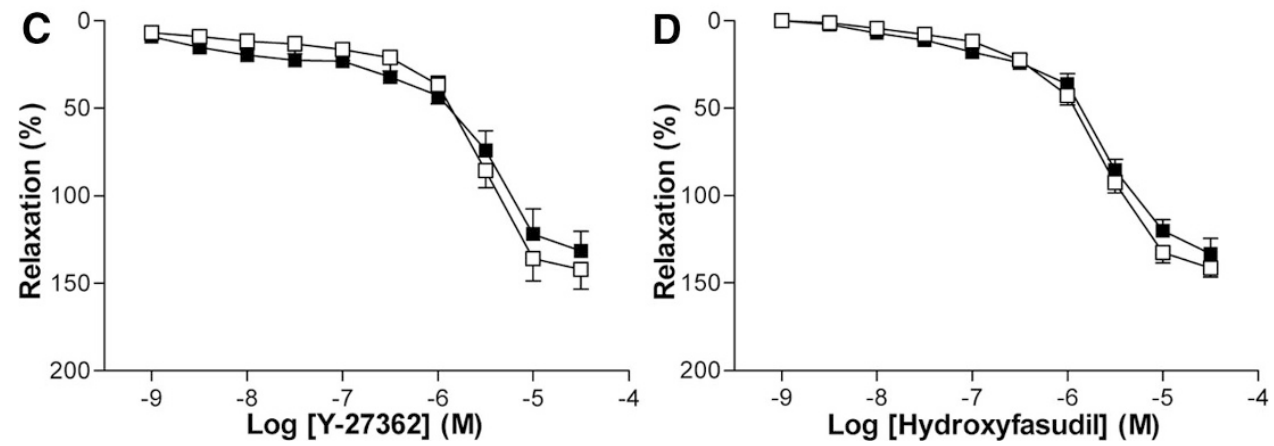

sure to chronic hypoxia (21). In turn, chronic hypoxia has been reported to elevate vascular sGC abundance and activity in some studies (12), but decrease it in others (22). In the present study, we observed that the relaxation induced by the cell-permeable analog of cGMP, 8-Br-cGMP, was similar in the DA from normoxic and hypoxic fetuses, indicating that signaling events coupling cGMP to relaxation were not affected by chronic hypoxia. Taking together, our results suggest that chronic hypoxiainduced impairment of NO-evoked relaxation is due to a reduced sGC activity. However, an additional impairment the endothelial NO synthase or an increase in phosphodiesterase-mediated catalysis of cGMP cannot be discarded.

Our study also reports that adrenergic agonist-induced contractions to norepinephrine and phenylephrine were enhanced in the DA from chicken fetuses exposed to chronic hypoxia during incubation. On the other hand, the DA relaxations induced by the $\beta$-adrenoceptor agonist isoproterenol were impaired in the hypoxic fetuses. Accordingly, other investigators reported that femoral artery constriction in response to adrenergic agonists was significantly enhanced in femoral arteries from rats (23) and lambs (14) gestated under hypoxia. In contrast, chronic hypoxia impaired the contraction evoked by $\alpha$-adrenergic agonists in pulmonary arteries (14). Previously, we demonstrated that norepinephrine and phenylephrine induced a developmentally increased contraction of the chicken DA (8). Interestingly, the relaxation induced by isoproterenol decreased with development (10). Therefore, the changes induced by hypoxia in DA adrenergic responsiveness mimic the changes induced by development, suggesting that the effect of hypoxia might be consequence of a developmental acceleration. In addition, the impairment of ACh- and SNP-mediated relaxation, which is a characteristic feature of the mature chicken DA (9), was also observed in the hypoxic fetuses. However, other features of the mature chicken DA, such as the enhanced responsiveness to $\mathrm{O}_{2}, \mathrm{KCl}, \mathrm{H}_{2} \mathrm{O}_{2}, \mathrm{ET}-1$, or 4 -AP $(8,24)$ were not present in the DA of the hypoxic animals.

Activation of the RhoA/Rho-kinase pathway can induce $\mathrm{Ca}^{2+}$ sensitization, a phenomenon in which sustained vasoconstriction occurs, independent of ongoing increases in cytosolic $\mathrm{Ca}^{2+}$ $(25,26)$. Recently, Rho kinase activation has been implicated in DA constriction in several mammalian species $(25,26)$. Our observation of the Rho-kinase inhibitors Y-27632 and hydroxyfasudil concentration dependently decreasing tone of $\mathrm{KCl}$ precontracted chicken DA suggests that this pathway also plays a role in the regulation of $\mathrm{DA}$ contraction in this species. $\mathrm{Nu}$ merous experimental evidences indicate that chronic hypoxia augments Rho kinase-induced vascular smooth muscle $\mathrm{Ca}^{2+}$ sensitization, particularly in the pulmonary vasculature $(13,27)$ McNamara et al. (13) reported that pulmonary vascular RhoA is activated and Rho-kinase activity is increased in rat pups by exposure to hypoxia from birth for $14 \mathrm{~d}$. Moreover, hypoxiainduced RhoA expression in the lung is age dependent and found to be greatest in the fetus (27). In the present study, we observed that the relaxation evoked by Y-27632 and hydroxyfasudil was similar in DAs from normoxic and hypoxic fetuses. This indirectly suggests that Rho-kinase activity in the chicken DA was unaffected by chronic prenatal hypoxia.

The chicken DA presents morphologic and functional heterogeneity along its path between the pulmonary artery and the aorta $(8,24)$. Thus, the pulmonary side shows the structure of a muscular artery and responds to $\mathrm{O}_{2}$ with contraction, whereas the aortic part shows the morphology of an elastic artery and relaxes in response to $\mathrm{O}_{2}(8,24)$. In addition, $\mathrm{ACh}, \mathrm{SNP}$, and the NOindependent stimulator of sGC BAY 41-2272 induced larger relaxations in the aortic side of the vessel (9), whereas isoproterenol, forskolin, and the phosphodiesterase 3 inhibitor milrinone evoked larger relaxations in the pulmonary side (10). The reac- 
tivity studies of the present work were exclusively focused on the pulmonary side, which appears to be the "real" DA in the chicken. Bergwerff et al. (28) demonstrated that the distal elastic part of the chicken DA is mesodermal in origin and is the result of the incorporation of dorsal aorta tissue, whereas the muscular pulmonary side was shown to consist almost exclusively of neural crest derived cells. In the present work, we observed that the proportion of DA with muscular morphology was significantly reduced in the hypoxic animals. In addition, and although the in situ diameter of the DA was not affected by hypoxia, the functional diameter (i.e., the one at which the vessels showed maximal $\mathrm{K}^{+}$-induced contraction) was higher in the hypoxic group. With our present results, we can only speculate about these findings. However, and interestingly, numerous studies demonstrated that exposing animals to chronic hypoxia results in morphologic and functional changes in the neural crest-derived, oxygen-sensing cells of the carotid body (29). The specific effects of chronic hypoxia in the neural crest-derived cells of the DA and in the vascular elastic properties warrant further investigation.

As mentioned in the introduction, there have been reported signs of accelerated (3) or abnormal (4) DA development in preterm infants with IUGR. Recently, Rakza et al. (2) described that the DA is larger in infants with IUGR than in eutrophic preterm infants, as soon as $6 \mathrm{~h}$ after birth. In our chicken model, and with the exception of the above discussed shortening of the pulmonary segment, no other signs of morphologic alterations were found and the CSAs of the DA lumen and wall were comparable between normoxic and hypoxic 19-d fetuses. This suggests that at this stage of development the DA maintains a similar degree of patency in both groups. The 19-d fetuses used in the present study were noninternally pipped. On day 19 of incubation, the fetus internally pips by piercing the air cell inner membrane with its beak and begins lung ventilation. During the internal pipping, the relative blood flow to the chorioallantoic membrane progressively declines, whereas blood flow to the lungs increases (24). However, the presence of the ductal shunt is still necessary during internal pipping. In fact, Belanger et al. (24), reported that internal pipping did not induce significant changes in chicken DA diameter but these changes were observed during external pipping. At this stage, ductal closure was associated with a breakdown of the internal elastic lamina, migration of smooth muscle cells into the neointimal zone, and swelling and detachment of the endothelial layer $(9,24)$. By day 2 posthatching the lumen of the proximal portion of the DA is completely occluded (24). Whether the structural and functional alterations that we described in the present work accelerate or delay this process remains to be investigated.

\section{REFERENCES}

1. Fang S 2005 Management of preterm infants with intrauterine growth restriction. Early Hum Dev 81:889-900

2. Rakza T, Magnenant E, Klosowski S, Tourneux P, Bachiri A, Storme L 2007 Early hemodynamic consequences of patent ductus arteriosus in preterm infants with intrauterine growth restriction. J Pediatr 151:624-628

3. King DT, Emmanouilides GC, Andrews JC, Hirose FM 1980 Morphologic evidence of accelerated closure of the ductus arteriosus in preterm infants. Pediatrics 65:872-880

4. Ibara S, Tokunaga M, Ikenoue T, Murata Y, Hirano T, Asano H, Uemura Y 1994 Histologic observation of the ductus arteriosus in premature infants with intrauterine growth retardation. J Perinatol 14:411-416
5. Ruijtenbeek K, le Noble FA, Janssen GM, Kessels CG, Fazzi GE, Blanco CE, De Mey JG 2000 Chronic hypoxia stimulates periarterial sympathetic nerve development in chicken embryo. Circulation 102:2892-2897

6. Ruijtenbeek K, Kessels LC, De Mey JG, Blanco CE 2003 Chronic moderate hypoxia and protein malnutrition both induce growth retardation, but have distinct effects on arterial endothelium-dependent reactivity in the chicken embryo. Pediatr Res 53:573579

7. Villamor E, Kessels CG, Ruijtenbeek K, van Suylen RJ, Belik J, de Mey JG, Blanco CE 2004 Chronic in ovo hypoxia decreases pulmonary arterial contractile reactivity and induces biventricular cardiac enlargement in the chicken embryo. Am J Physiol Regul Integr Comp Physiol 287:R642-R651

8. Agren P, Cogolludo AL, Kessels CG, Perez-Vizcaino F, De Mey JG, Blanco CE, Villamor E 2007 Ontogeny of chicken ductus arteriosus response to oxygen and vasoconstrictors. Am J Physiol Regul Integr Comp Physiol 292:R485-R496

9. Agren P, van der Sterren S, Cogolludo AL, Frazziano G, de Mey JG, Blanco CE, Villamor E 2008 Developmental changes in endothelium-dependent relaxation of the chicken ductus arteriosus. J Physiol Pharmacol 59:55-76

10. Agren P, van der Sterren S, Cogolludo AL, Blanco CE, Villamor E 2008 Developmental changes in the effects of prostaglandin $\mathrm{E}(2)$ in the chicken ductus arteriosus. J Comp Physiol [B] [Epub ahead of print]

11. Marino M, Beny JL, Peyter AC, Bychkov R, Diaceri G, Tolsa JF 2007 Perinatal hypoxia triggers alterations in $\mathrm{K}+$ channels of adult pulmonary artery smooth muscle cells. Am J Physiol Lung Cell Mol Physiol 293:L1171-L1182

12. Li D, Laubach VE, Johns RA 2001 Upregulation of lung soluble guanylate cyclase during chronic hypoxia is prevented by deletion of eNOS. Am J Physiol Lung Cell Mol Physiol 281:L369-L376

13. McNamara PJ, Murthy P, Kantores C, Teixeira L, Engelberts D, van Vliet T, Kavanagh BP, Jankov RP 2008 Acute vasodilator effects of Rho-kinase inhibitors in neonatal rats with pulmonary hypertension unresponsive to nitric oxide. Am J Physiol Lung Cell Mol Physiol 294:L205-L213

14. Herrera EA, Pulgar VM, Riquelme RA, Sanhueza EM, Reyes RV, Ebensperger G, Parer JT, Valdez EA, Giussani DA, Blanco CE, Hanson MA, Llanos AJ 2007 High-altitude chronic hypoxia during gestation and after birth modifies cardiovascular responses in newborn sheep. Am J Physiol Regul Integr Comp Physiol 292:R2234-R2240

15. Kajino H, Goldbarg S, Roman C, Liu BM, Mauray F, Chen YQ, Takahashi Y, Koch CJ, Clyman RI 2002 Vasa vasorum hypoperfusion is responsible for medial hypoxia and anatomic remodeling in the newborn lamb ductus arteriosus. Pediatr Res 51:228-235

16. Sutendra G, Michelakis ED 2007 The chicken embryo as a model for ductus arteriosus developmental biology: cracking into new territory. Am J Physiol Regul Integr Comp Physiol 292:R481-R484

17. Thebaud B, Wu XC, Kajimoto H, Bonnet S, Hashimoto K, Michelakis ED, Archer SL 2008 Developmental absence of the $\mathrm{O}_{2}$ sensitivity of L-type calcium channels in preterm ductus arteriosus smooth muscle cells impairs $\mathrm{O}_{2}$ constriction contributing to patent ductus arteriosus. Pediatr Res 63:176-181

18. Paffett ML, Walker BR 2007 Vascular adaptations to hypoxia: molecular and cellular mechanisms regulating vascular tone. Essays Biochem 43:105-119

19. Peyter AC, Muehlethaler V, Liaudet L, Marino M, Di Bernardo S, Diaceri G, Tolsa JF 2008 Muscarinic receptor M1 and phosphodiesterase 1 are key determinants in pulmonary vascular dysfunction following perinatal hypoxia in mice. Am J Physiol Lung Cell Mol Physiol 295:L201-L213

20. Phillips SA, Olson EB, Morgan BJ, Lombard JH 2004 Chronic intermittent hypoxia impairs endothelium-dependent dilation in rat cerebral and skeletal muscle resistance arteries. Am J Physiol Heart Circ Physiol 286:H388-H393

21. Xue Q, Ducsay CA, Longo LD, Zhang L 2008 Effect of long-term high-altitude hypoxia on fetal pulmonary vascular contractility. J Appl Physiol 104:1786-1792

22. Hassoun PM, Filippov G, Fogel M, Donaldson C, Kayyali US, Shimoda LA, Bloch KD 2004 Hypoxia decreases expression of soluble guanylate cyclase in cultured rat pulmonary artery smooth muscle cells. Am J Respir Cell Mol Biol 30:908-913

23. Williams SJ, Campbell ME, McMillen IC, Davidge ST 2005 Differential effects of maternal hypoxia or nutrient restriction on carotid and femoral vascular function in neonatal rats. Am J Physiol Regul Integr Comp Physiol 288:R360-R367

24. Belanger C, Copeland J, Muirhead D, Heinz D, Dzialowski EM 2008 Morphological changes in the chicken ductus arteriosi during closure at hatching. Anat Rec (Hoboken) 291:1007-1015

25. Kajimoto H, Hashimoto K, Bonnet SN, Haromy A, Harry G, Moudgil R, Nakanishi T, Rebeyka I, Thebaud B, Michelakis ED, Archer SL 2007 Oxygen activates the Rho/Rho-kinase pathway and induces RhoB and ROCK-1 expression in human and rabbit ductus arteriosus by increasing mitochondria-derived reactive oxygen species: a newly recognized mechanism for sustaining ductal constriction. Circulation 115:1777-1788

26. Clyman RI, Waleh N, Kajino H, Roman C, Mauray F 2007 Calcium-dependent and calcium-sensitizing pathways in the mature and immature ductus arteriosus. Am J Physiol Regul Integr Comp Physiol 293:R1650-R1656

27. Bailly K, Ridley AJ, Hall SM, Haworth SG 2004 RhoA activation by hypoxia in pulmonary arterial smooth muscle cells is age and site specific. Circ Res 94:13831391

28. Bergwerff M, Verberne ME, DeRuiter MC, Poelmann RE, Gittenberger-de Groot AC 1998 Neural crest cell contribution to the developing circulatory system: implications for vascular morphology? Circ Res 82:221-231

29. Wang ZY, Bisgard GE 2005 Postnatal growth of the carotid body. Respir Physiol Neurobiol 149:181-190 